\title{
A SELF-DETERMINATION THEORY BASED MOTIVATIONAL MODEL ON INTENTIONS TO DROP OUT OF VOCATIONAL SCHOOLS IN VIETNAM
}

\author{
${ }^{1}$ Bui Thi Thuy Hang, ${ }^{2}$ Amrita Kaur \& \\ ${ }^{3}$ Abdul Hamid Busthami Nur \\ ${ }^{1}$ Hanoi University of Science and Technology, Vietnam \\ ${ }^{2 \& 3}$ School of Education and Modern Languages \\ Universiti Utara Malaysia, Malaysia
}

${ }^{2}$ Corresponding author: amrita@uum.edu.my

\begin{abstract}
Purpose - Student motivation for positive academic outcome and persistence at school is significantly affected by personal and environmental factors. Anchored in self-determination theory, this study tested a motivational model which looked at how support in terms of perceived teacher autonomy and from school administration constituted the key factors in explaining school climate. The study was also primarily concerned with how these crucial factors would help predict student motivation and perceived competence, and how they in turn, would affect student school performance and help predict student drop out intentions.
\end{abstract}

Methodology - This model was tested on 277 first year vocational college students in Hanoi, Vietnam. Data was collected through a self-report questionnaire. The hypothesized relationships were tested using partial least squares (WarpPLS 3.0).

Findings - The structural model analysis carried out suggested that all the hypothesized relationships were statistically significant. Student experience of autonomy support from teachers and administrators predicted motivation and perceived competence, which in turn predicted student school performance and intentions to drop out from school. 
Significance - The findings and its implication were discussed in relation to the type of teacher classroom behaviour and the nature of school administration style that would be required to facilitate autonomy support for the students to enhance their motivation and help them gain competence.

Keywords: Self-determination theory, vocational education, drop out, motivation.

\section{INTRODUCTION}

Organizations such as the Asian Development Bank (ADB) and the United Nations Educational, Scientific and Cultural Organization (UNESCO) which monitor and facilitate international development have recommended the provision of the Technical and Vocational Education and Training (TVET) programme as a crucial measure for economic prosperity in developing countries (ADB, 2008; UNESCO, 2012). The Southeast Asia Ministers of Education Organization (SEAMEO) Secretariat director regarded the TVET as an effective means for ensuring the gainful employment of youths in the region, and thus would in turn, bring national and regional economic advantage and help alleviate poverty (Jeradechakul, 2013). However, recruiting students into the TVET programme and having them persist in these schools has remained a critical educational challenge across several countries in the world. For example, less than one third of students in TVET programmes finished their courses in Australia (Rosenberg, 2011). Statistics on the completion of TVET programmes obtained from the department of higher education and training in South Africa was varied across fields of study. However, the numbers pointed to the fact that dropout rates from TVET programmes were significantly high (DHET, 2014). High dropout rates in TVET programmes have remained a key concern for China as well. The numbers reported showed that dropout rates were as high as $10.7 \%$ across all regions in China (Yao et al., 2013). Other countries such as India, Pakistan, Ethiopia, Albania and Kenya have also been struggling with similar challenges of students dropping out of the TVET programmes in the country (see Janjua \& Irfan, 2008). 
In Vietnam, the TVET programme was differentiated in terms of the type of offerings found in two types of institutions and one occupational training programme, namely in a vocational college (three years after high school), in a vocational secondary school (1-2 years after high school), and in an elementary occupational programme (3-6 months of training). According to the data from the general directorate of vocational training in Vietnam, in the year 2011 , there were a total of 57,955 students enrolled in vocational training programmes in 101 vocational institutions across Vietnam. However, only 49,055 of these trainees could finish the courses and receive their diplomas. The figures in the report clearly showed that approximately $15 \%$ of students dropped out of vocational college programmes (Báo cáo dạy nghề Việt Nam, 2011, Tổng cục dạy nghề, Viện nghiên cứu khoa học dạy nghề). According to the report in the year 2012, out of a total of 46,116 students enrolled in 90 vocational colleges across Vietnam, only 33,361 students could participate in the final examination. The remaining 12,755 students either dropped out of college or did not encounter favorable conditions to enable them to take their final examination; therefore, the unfortunate state of affairs being only approximately $62 \%$ of enrolled students could finish their vocational training.

In this regard, investigating factors that led to the increasing number of dropouts as well as other factors often associated with dropout prevention has become a matter of significant interest to researchers. Previous studies have suggested a number of economic (e.g., low socioeconomic status) and social factors (e.g., singleparent families, low parental education) that could be linked to the problem of dropping out of school (Fowler \& Walberg, 1991; Haller \& Virkler, 1993). Jordan, Lara, and McPartland (1994) posited that there were two major categories of factors, namely the push and pull factors that could trigger students to drop out of their studies. According to them push factors originated from within the school environment, whereas pull factors had its origin from outside the school. Although, teachers and the school administration could not exercise any control over the external factors causing students to drop out of school, they nevertheless could act to develop a school environment that could help to build up the necessary inner motivational resources required by students to persist in their studies (Hardre \& Reeve, 2003; Reeve, 2006). As stated earlier, this study 
was aimed at testing a motivational model anchored in the principles of self-determination theory (SDT). Similar motivational models have been tested in previous studies studying drop out intentions of high school students in the western context (Hardre \& Reeve, 2003; Vallerand, Fortier, \& Guay, 1997). However, given the increasing importance of vocational education, and yet the seemingly persistent unabated problems of students dropping out of such educational programmes, the present study felt that it was particularly important to also test this motivational model on the nature of motivation found among vocational students in the eastern context as well.

\section{Self-Determination Theory}

Self-determination theory (SDT) is a theory of human motivation and it has proposed that humans needed to fulfill the following three basic psychological needs - autonomy, competence and relatedness. These needs were considered crucial for healthy functioning across several realms of human life (Deci \& Ryan, 2000; Ryan \& Deci, 2000). The need for autonomy referred to behaviors that were volitional and self-initiated. The need for competence was defined as a feeling of being efficient while interacting within the social environment and the need for relatedness referred to the bonding or sense of belongingness between individuals or groups. The theory also posited that in a variety of contexts, satisfaction of these needs facilitated motivation among human beings (Deci \& Vansteenkiste, 2004).

Self-determination theory (henceforth SDT) also made the point that behaviors could be intrinsically or extrinsically motivated. Intrinsically motivated behaviors would have internal locus of control meaning that one's actions were performed for pleasure and satisfaction. In contrast, extrinsically motivated behaviors would be controlled by external demands and they were not carried out in light of an interest in the activity itself (Deci \& Ryan, 1985;1991). SDT has presented four types of extrinsic motivational behaviors on a continuum that moved from lower to higher forms of motivation. Both external regulation and introjected regulation were considered controlling forms of motivation, whereas identified regulation, integrated regulation, and intrinsic motivation were regarded as self-determined motivation. In external regulation, an individual's 
behaviour would be controlled by external contingencies such as rewards or punishments. On the other hand, introjected behaviours were seen as partially internalized actions that might be performed to avoid guilt or gain recognition. Motivation deriving from identified regulation would result in actions that might not be interesting to perform but were still personally valuable to individuals. Finally, integrated regulation was considered as the most selfdetermined form of extrinsic motivation whereby behaviour was fully internalized and self-determined (Deci \& Ryan, 1985; 1991). Therefore, in learning organizations which had created an optimal context that supported basic needs, this would result in facilitating motivation.

It is evident that TVET programmes play a central role in the economic prosperity of developing countries. With the provision of TVET programmes a great number of unskilled and unemployed individuals could be trained in essential skills and competences to be able to earn a livelihood. However, the general perception towards TVET programmes in developing countries is poor as it carries the negative impression of a non-academic field or the second choice and not being considered part of mainstream education (Shenmiao, 2011). This rather unfavourable perception has somewhat also contributed as a push factor for TVET students to drop out from their programme of study. Therefore, in TVET institutions it has become essential to create a learning environment that could facilitate satisfaction of the SDT's three psychological needs so as to enable students the opportunity to experience higher self-esteem, to take responsibility of their actions, and to feel connected to the institution and the choices they have made. Self-determination theory highlights the importance of satisfying the need to be competent, especially for the tasks that will require effort and dedication, for example, in terms of satisfactory performance at school or at the workplace. It represents the need to accept challenging tasks and master them to feel efficacious. Therefore, if teachers and administrators are able to create an environment or culture that can facilitate experiences of autonomy and competence, students will be able to develop identified regulation. When this happens, students can begin to value learning and appreciate the importance of completing their studies and become professionally trained graduates ready to take on the world of work. 


\section{School Social Context and Motivation Model}

Student motivation is a key variable when studying the factors leading to the problem of school dropouts. "Motivation represents the hypothetical construct used to describe the internal or external forces that produce the initiation, direction and intensity and persistence of behavior" (Vallerand \& Thrill, 1993, p. 18). Vallerand's (1997) model postulated that social contextual factors could influence different types of motivation through the satisfaction of the three essential psychological needs outlined in SDT. The empirical literature on self-determination theory has shown that the satisfaction of the need for student autonomy can be achieved through teacher autonomy support (Reeve, 2006), parental autonomy support (Vallerand, Fortier, \& Guay, 1997) and administration autonomy support (Sénécal, Vallerand, \& Pelletier, 1992). Reeve and colleagues (Reeve \& Jang, 2006; Reeve, 2006) have defined teacher autonomy supportive (TAS) behaviors as teachers listening carefully to students and acknowledging their perspective, providing them with opportunities for active participation, allowing them to work in their preferred way, allowing students to manipulate teaching objects, communicating a rationale for learning, giving encouragement and providing praise as rewards (See Kaur, Awang-Hashim, \& Noman, 2015). Similarly, administration autonomy support (AAS) is characterized by giving students more options to choose, providing more opportunities for the application of knowledge by doing, and opportunity to interact openly (Hang, Kaur, \& Patil, 2015; Sénécal, Vallerand, \& Pelletier, 1992). Teachers and school administration play a key role in defining the social environment of schools. Therefore, autonomy support from these key stakeholders is significant since the school administration and teachers have a direct influence on student motivation (Vallerand, 1997). The literature relating to SDT provides much empirical evidence that autonomy support from stakeholders involved in the educational process directly or indirectly facilitates student motivation and has positive effects on academic outcome which, in turn, reduces the risk of students dropping out of their studies (Alivernini \& Lucidi, 2011, Vallerand, Fortier \& Guay, 1997). Similarly, an autonomy supportive school environment that supports choice and selfinitiation of activity will let individuals feel efficacious and, in turn, will fulfill the need for competence (Ryan \& Deci, 2000). When 
students perceived their school environment (i.e., teachers and administration in this study) as autonomy supportive, they reported higher self-determined motivation, as well as felt more competent (Ryan \& Grolnick, 1986; Kaur, Awang-Hashim, \& Noman, 2015). Both these student experiences, feeling motivated and feeling competent contributed towards their enhanced school performance (Vallerand, 1997).

The hypothesized motivation model shown in Figure 1 is much closer to the one examined in Hadre and Reeve (2003), except that school administration autonomy support was added as another variable since the focus of the present study was on the role of agents involved in the school context. There had been comments that such a model of motivation did not claim a direct relationship between student motivation and the potential of dropping out of school. (Hardre \& Reeve, 2003; Vallerand, Fortier, \& Guay, 1997). On the basis of the fundamental tenets of self-determination theory, the effects of the social agents (TAS and AAS) working in school contexts were hypothesized to be mediated by motivation and perceived competence which (a) would directly predict school performance and intentions to drop out, and (b) would indirectly predict intention to drop out because of school performance. The hypotheses for this model were as enumerated in Table 2 in the results section.

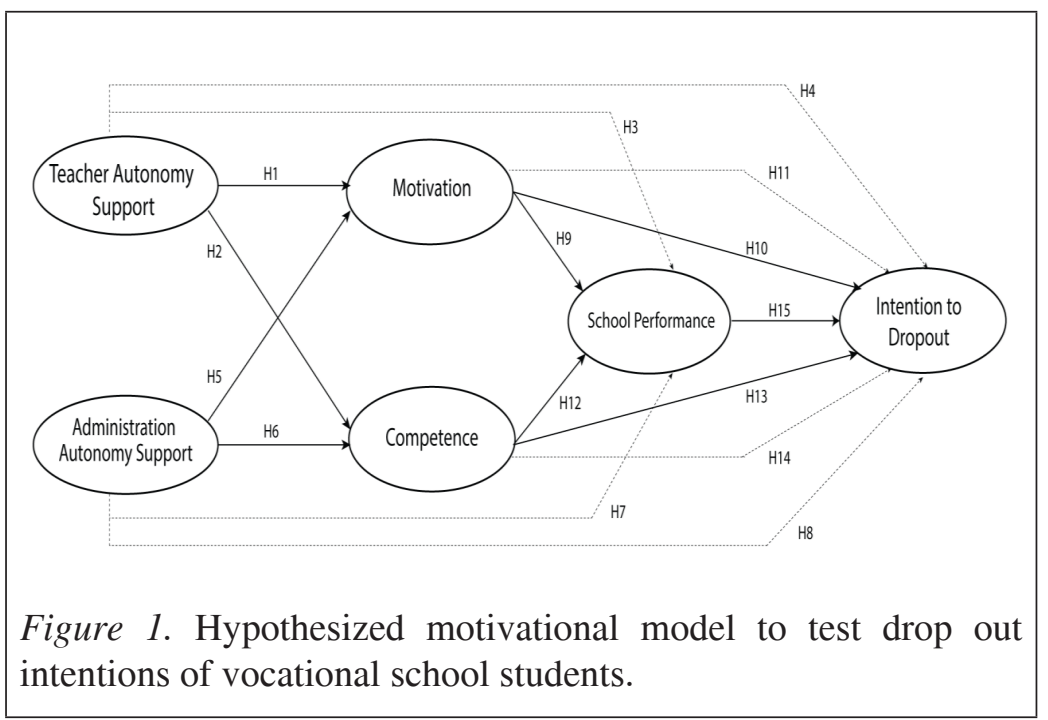




\section{METHODOLOGY}

\section{Participants}

The population sample for the study was made up of students enrolled in the first year of a Vocational College in Hanoi; therefore purposive sampling was employed to recruit the participants of the study. A total of 277 students ( 24 females, 253 males) participated in the study. Their ages ranged from 17 to 23 years, with a mean age of 19.5. These students were enrolled in five classes of five specialized courses, namely: Accounting (20\%), Electric-electronic (27\%), Automobile technology (21\%), Mechanics (14\%), and Technology $(18 \%)$.

\section{Measures}

Six questionnaires were used to assess the following six variables of concern in the study, namely: school administration autonomy support, teacher autonomy support, motivation, perceived competence, school performance and intention to persist versus drop out. All the questionnaire items were rated on a 5-point Likert scale, ranging from not at all in agreement (1) to completely in agreement (5).

Perceived school administration autonomy support. Perceived school administration autonomy support referred to students' perception or their experiences of autonomy support provided by the school administration. It was assessed using a scale developed from the School Administration Autonomy Support Scale (Vallerand, Fortier, \& Guay, 1997). This scale consisted of four items (e.g., "School provides students with lots of opportunity to choose course schedules and disciplines"). Higher average scores represented a higher level of perceived school administration autonomy support. The internal consistency of the scale used in the present study was found to be .64 .

Perceived teacher autonomy support. Perceived teacher autonomy support referred to students' perception or their experiences of autonomy support provided by the school teachers. Perceived teacher autonomy support was assessed using a questionnaire developed from the Learning Climate Questionnaire (LCQ; Williams \& Deci, 
1996). This measure consisted of three items asking students to think about the degree to which the teachers they have taken classes from in their school supported their autonomy (e.g., "My teachers provide me with choices and options"). Higher average scores represented a higher level of perceived teacher autonomy support. The reliability coefficient computed by Cronbach's alpha was found to be 67 .

Academic motivation scale: Academic motivation referred to student motivation towards educational activities. The students' self-determined motivation was assessed using a scale constructed from the French version of the Academic Motivation Scale (Echelle de Motivation en Education (Vallerand, Blais, Brière, \& Pelletier, 1989). This measure consisted of five items. The scale was designed to ask students the reasons why they were attending college. In the present study, on the basis of factor loading, four items from Identified regulation (e.g., I go to this school because I think that this school will help me develop my professional competence), and one item from Intrinsic motivation (e.g., I go to this school because I would like to know more about the career) were retained in the scale. The reliability coefficient computed by Cronbach's alpha was found to be .68 .

Perceived competence: Perceived competence referred to student perception of their abilities to perform. Students' perceived competence in the education domain was often assessed using a questionnaire developed by Williams and Deci (1996). The scale comprised three items

(e.g., "I feel confident in my ability to study at this school) and reported an internal consistency of .68.

School performance:School performance referred to the academic progress of students. It was assessed using a scale developed by Hardre and Reeve (2003) to assess anticipated academic performance. The scale comprised two items (e.g., "I expect to achieve good results in studying") and had an internal consistency of. 59.

Intentions to drop out: Intentions to drop out referred to student aspiration or aim to finish or not to finish a programme of study. It was assessed using a scale from Hardre and Reeve (2003). The 
scale comprised three items (e.g., "I sometimes feel unsure about continuing my studies at this school") and had an internal consistency of .74.

\section{Procedure}

At the end of the first semester (December 2014), vocational college students in the first-term in five classes were asked to complete the questionnaires described above. Formal permission from the college was obtained to conduct the study and the participation from students was voluntary. A research assistant administered the questionnaire during regular classrooms when the lecturers were not present in the class. The questionnaires were presented in the students' native language, i.e., Vietnamese. The administrator explained the type of questions included in the questionnaire. Students were informed that the researchers were interested in understanding students' perspective of their school and this included their experiences about the school administration and their lecturers. The administrator ensured students that the confidentiality of their answers would be maintained. In each class students took 20-30 minutes to answer the questions. In the end students were thanked for their participation.

\section{RESULTS}

\section{Measurement Model}

The proposed model of hypothesized relationships was statistically tested using partial least squares WarpPLS 3.0 (Ringle, Wende, $\&$ Becker, 2015). Prior to structural model analysis, the study conducted measurement model analysis to test the relationship between indicators and their constructs. The measurement model was used to assess the reliability and validity of the indicators in relation to their specific constructs. The six constructs in the models, namely teacher autonomy support (TAS), administrative autonomy support (AAS), student motivation (MOT), perceived competence (PC), school performance (SP), and drop out intention (DO) were analyzed. The result of the analysis showed that all the indicators were significant and above 0.60 loading level, which implied that all 
the indicators shared more variance with their respective constructs than with the error variance. In other words, the loading with a minimum of .60 is important as it indicated that the measure was able to account for at least $60 \%$ of variances from the underlying latent variables (Chin, 1988).

The measurement model was also assessed for its convergent validity by applying the following three procedures proposed by Fornell and Larcker (1981) and Chin, (1988), namely (i) the item reliability of each measure should be equal to or exceed the recommended point of .60, (ii) the composite reliability (CR) of the construct should be equal to or exceed the threshold point of. 70, and (iii) the average variance extracted (AVE) should be $\geq .50$. The result of the measurement model analysis for all the six constructs in this study satisfied all these three criteria.

Academic autonomy support reported the following values: $\mathrm{CR}=$ $0.86 ; \mathrm{AVE}=0.68$ and factor loading ranged from .81 to .83 . Teacher autonomy support reported the following values: $\mathrm{CR}=0.86$; $\mathrm{AVE}=$ 0.62 and factor loading ranged from .70 to .84 . Perceived competence reported the following values: $\mathrm{CR}=0.85 ; \mathrm{AVE}=0.67$ and factor loading ranged from .76 to 83 . Academic motivation reported the following values: $\mathrm{CR}=0.87 ; \mathrm{AVE}=0.58$ and factor loading ranged from .70 to .82 . School performance reported the following values: $\mathrm{CR}=0.90 ; \mathrm{AVE}=0.82$ and factor loading ranged from .90 to .91 , and drop out reported the following values: $\mathrm{CR}=0.92$; $\mathrm{AVE}=0.81$ and factor loading ranged from .88 to .91 .

Discriminant validity measures whether each item shares more variance with its construct than other items. It is analyzed by comparing the square root of AVEs to the correlation between construct. When the square root of AVE of construct is greater than the correlation between construct, it is considered valid. Table 1 displays the results of the square root of AVEs of constructs in the diagonal and the correlation among the constructs in the offdiagonal. It shows that discriminant validity is achieved because all scores in the diagonal are greater than their respective off-diagonal scores. Overall, the results showed that the measurement model was reliable and valid. 
Table 1

Discriminant Validity for the Construct Measured

\begin{tabular}{lcccccc}
\hline & AAS & TAS & PC & Mot & SP & DO \\
\hline Academic Autonomy Support & $\mathbf{0 . 8 2}$ & & & & & \\
Teacher Autonomy Support & 0.75 & $\mathbf{0 . 7 8}$ & & & & \\
Perceived Competence & 0.59 & 0.62 & $\mathbf{0 . 8 1}$ & & & \\
Motivation & 0.62 & 0.62 & 0.65 & $\mathbf{0 . 7 6}$ & & \\
School Performance & 0.54 & 0.54 & 0.65 & 0.63 & $\mathbf{0 . 9 1}$ & \\
Drop Out & -.45 & -0.47 & -0.49 & -0.53 & -0.49 & $\mathbf{0 . 9 0}$ \\
\hline
\end{tabular}

Note. Diagonal element: Square root of AVE; Off-diagonal: correlation between constructs

Significant at $\mathrm{p}<.001$

\section{Structural Model Analysis}

A structural model was used in this study to test the hypothesized relationship among factors in the model. The present study had made the claim that teacher autonomy support (TAS) and administration autonomy support (AAS) as mediated by student motivation (MOT), student perceived competence (PC), and student school performance (SP) would be able to predict student intention to drop out (DP).

In this study, the PLS structural model used a coefficient of determination $\left(R^{2}\right)$ and test of significance $(\beta)$ with t statistics. The coefficient of determination $\left(\mathrm{R}^{2}\right)$ represents the predictive ability of the research model that has proposed a relationship between exogenous and endogenous variables. For the test of significance $(\beta)$, the relationship of the related path between an independent variable and the dependent variables is tested through t value which is obtained from bootstrap resampling methods. In the present study, the $t$ value for testing of the significance was obtained by running 5000 bootstrapped samples from the original 277 cases. As shown in Figure 2, the coefficient of determination $\left(\mathrm{R}^{2}\right)$ for motivation was .451 , for competence was .429 , for school performance was.502, and for school dropout was .342 . Thus, it can be seen that the overall model helped explain the $34.2 \%$ variance.

As shown in Figure 2, the test of significance, the path coefficient between teacher autonomy support, and motivation was $\beta=.356$ 
$(\mathrm{t}=4.60, \mathrm{p}<.0001)$. Teacher autonomy support and perceived competence was $\beta=.420 \quad(\mathrm{t}=5.21, \mathrm{p}<.0001)$. A statistically significant positive effect supported $\mathrm{H} 1$ and $\mathrm{H} 2$ by indicating that teacher autonomy support would predict student motivation and competence. Similarly, H5 and H6 were also supported as path coefficient between administration autonomy support and motivation was $\beta=.362(\mathrm{t}=4.82, \mathrm{p}<.0001)$ and administration autonomy support and perceived competence $\beta=.278(\mathrm{t}=3.17, \mathrm{p}<.005)$, which indicated that administration autonomy support would also predict student motivation and competence. The path coefficient between student motivation and school performance was $\beta=.358(\mathrm{t}=6.50$, $\mathrm{p}<.0001$ ). A statistically significant positive effect supported H9, indicating that student motivation would predict school performance. However, the path coefficient for student motivation and intention to drop out was $\beta=-.303(\mathrm{t}=2.31, \mathrm{p}<.0001)$. It reported a statistically significant negative effect and supported H10, indicating that if students experienced enhanced motivation, it would have a negative effect on their intention to drop out. Similarly, the path coefficient between perceived competence and school performance was $\beta=$ $.419(\mathrm{t}=7.26, \mathrm{p}<.0001)$. A statistically significant positive effect supported $\mathrm{H} 12$, indicating that perceived competence would predict school performance. However, the path coefficient for perceived competence and intention to drop out was $\beta=-0.169(\mathrm{t}=2.79$, $\mathrm{p}<.005)$. It reported a statistically significant negative effect and supported H13, indicating that a higher perceived competence would have a negative effect on student intention to drop out. Finally, the path coefficient between school performance and dropout was $\beta$ $=.194(\mathrm{t}=2.75, \mathrm{p}<.005)$ which reported a statistically significant negative effect and supported H15, indicating that enhanced school performance would have a negative effect on student intention to drop out. Figure 2 provides the path coefficient and $t$ statistic where the $t$ value greater than 1.96 is considered significant at 0.05 level.

The path analysis also examined (as shown in Table 2) the significance of direct, indirect and total effects produced between independent and dependent variables. In the SP path, TAS with an indirect effect of .30 was the more effective variable than AAS with the indirect effect of .24 , indicating that teacher autonomy support was more effective in predicting student school performance. Similarly, in the DO path, TAS with an indirect effect of -.23 was 
the more effective variable than AAS with an indirect effect of -.21, indicating that teacher autonomy support was more effective in predicting student intention to drop out. However, between MOT and DO, the direct effect was -.30, indicating that it was more significant that the indirect effect of -.06. Similarly, between PC and DO the direct effect was -.16, indicating that it was more significant than the indirect effect of -.08. Thus, H3, H4, H7, H8, H11, H14 were supported. Altogether, for the dropout model it was revealed that student motivation had the most significant total effect (-.37) on drop out, indicating that student motivation was the variable that was most strongly predicting student intention to drop out, followed by PC (-.25), TAS (-.23), AAS (-.20) and SP (-.19).

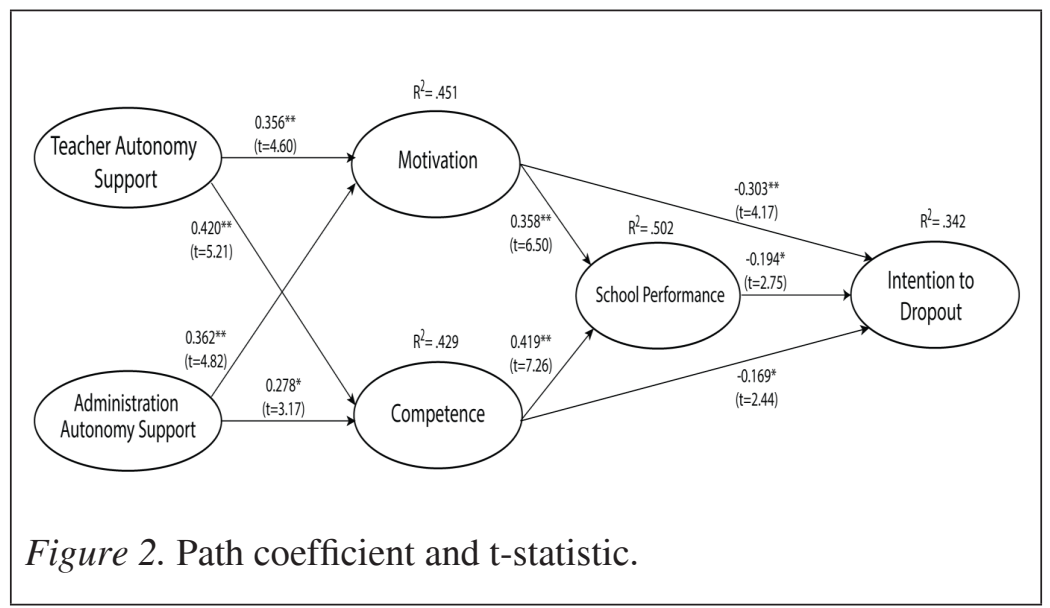

Table 2

Hypothesis Results

\begin{tabular}{llcrc}
\hline & Path & Direct effect & Indirect effect & Total effect \\
\hline H1 & TAS à Mot & $0.356^{* *}$ & & $0.356^{* *}$ \\
H2 & TAS à PC & $0.420^{* *}$ & & $0.420^{* *}$ \\
H3 & TAS à SP & & $0.303 * *$ & $0.303 * *$ \\
H4 & TAS à DO & & $-0.237 * *$ & $-0.237 * *$ \\
H5 & AAS à Mot & $0.362^{* *}$ & & $0.362^{* *}$ \\
H6 & AAS à PC & $0.278^{*}$ & & $0.278^{*}$ \\
\hline & & & & (continued)
\end{tabular}




\begin{tabular}{clrrr}
\hline & Path & Direct effect & Indirect effect & Total effect \\
\hline H7 & AAS àSP & & $0.246^{* *}$ & $0.246^{* *}$ \\
H8 & AAS à DO & & $-0.204^{* *}$ & $-0.204^{* *}$ \\
H9 & Motà SP & $0.358^{* *}$ & & $0.358^{* *}$ \\
H10 & Mot à DO (direct) & $-0.303^{* *}$ & $-0.069^{*}$ & $-0.372^{* *}$ \\
H11 & Mot à DO (indirect) & & & \\
H12 & PCàSP & $0.419^{* *}$ & & $0.419^{* *}$ \\
H13 & PCàDO (direct) & $-0.169^{*}$ & $-0.081^{*}$ & $-0.250^{*}$ \\
H14 & PCàDO (indirect) & & & \\
H15 & SP à DO & $-0.194^{*}$ & & $-0.194^{*}$ \\
\hline
\end{tabular}

$* \mathrm{p}<.05 . * * \mathrm{p}<.001$.

Note. TAS- Teacher autonomy support; AAS-Administration autonomy support;

PC- Perceived competence; Mot-Academic motivation; SP- School performance;

DO-Drop out intention

\section{DISCUSSION}

This study explored the relationship of teacher autonomy support and administration autonomy support on student drop out intention through academic motivation, perceived competence and school performance. All the relationships were found to be statistically significant. The full model accounted for $34 \%$ of the variance for drop out intention. Therefore, the model supported the proposition from self-determination theory that autonomy support from teachers and administration would predict motivation, perceived competence and school performance among students, which in turn would affect students' intention to dropout. The model was able to make explicit the following relationship: if students experienced the provision of autonomy support in the school environment, their motivation and feeling of competence would increase and their intentions to drop out would decrease (Hardre \& Reeve, 2003; Vallerand, Fortier, \& Guay, 1997).

However, after examining the model closely for such a direct relationship, it became clear that student motivation was the factor which most determined student intention to drop out. Also, student motivation was the most significant factor in predicting students' school performance. However, when school performance was mediated between student motivation and drop out intention, the effect deteriorated. This seemed to challenge the traditional notion 
that school performance was the major factor in determining student intention to drop out (Battin-Pearson et al., 2000). On the other hand, the results also seemed to suggest that school performance was mediated strongly through perceived competence and was able to predict student intention to drop out. This was because fulfillment of the need for competence had made the students felt efficacious, which in turn would have encouraged them to take challenges and master the task of performing well in their studies. Thus, it would seem that if students' perceived competence was facilitated, their school performance would be enhanced and would affect intention to drop out or to persist more significantly. Overall, this model as tested out in the Asian context has corroborated the findings obtained in the previous models used in the western context (Hardre \& Reeve, 2003; Vallerand, Fortier, \& Guay, 1997). Moreover, the present model showed a greater variance $\left(\mathrm{R}^{2}=.34\right)$ in contrast to the previous model $\left(\mathrm{R}^{2}=.27\right)$ by Hardre and Reeve (2003). This might have been caused by the inclusion of an additional variable referred to as administrative autonomy support which was examined in this study.

The present study has highlighted the challenges of persistence among students to continue their studies in TVET programmes across the world and more specifically, in Vietnam. Its findings in the foregoing discussion have implications for the role of important agents involved in the school environment. The two critical agents investigated in the study were teachers and school administrators, and it was revealed that they both significantly influenced student motivation and perception of competence in the eastern context as well. The findings highlighted the fact that the school environment, along with school performance had played a fundamental role in the intention of students to drop out.

The present study has clearly shown that in vocational colleges, the teachers and administrators have an important role to play in creating the appropriate school environment that can help facilitate students' inner motivational resources (Reeve, 2006). As has been asserted by SDT, school environments that facilitated the provision of autonomy support would be able to encourage students to take self-initiated actions. Providing students the opportunities to choose would result in students feeling motivated and experiencing competence 
(Deci \& Ryan, 2000). The findings also showed that teachers and administrators were capable of creating environments that would not only promote students' academic performance, but also most importantly had discouraged students from dropping out of college. Such findings also have cross cultural implications, especially on the significance of the construct of autonomy in eastern cultures (Kaur, Awang-Hashim \& Noman, 2014). The autonomy supportive environment had shown similar effects in the eastern context as was the case in the western context (Hardre \& Reeve, 2003; Vallerand, Fortier, \& Guay, 1997). As such, teachers and administrators in Vietnam should deeply appreciate and value the significance of autonomy support in enhancing school performance and controlling drop out intentions. However, it must be readily admitted that the eastern set up for undergraduate education is more structured and regulated, and may thus not allow for the opportunity for students to experience volition and self-direction. It is in light of this realization that teachers and administrators must plan and act cautiously to provide opportunities for students to extend their capabilities and develop competence and feel motivated.

The TVET institutions in the developing countries are struggling with efforts to decrease the dropout rates and increase TVET quality. It is common in these developing countries to enrol a student in a TVET programme as the second option, the reason usually being because the student has either failed to make it in the mainstream education or has become incapable of continuing in the mainstream education. Besides this, the reduction in tuition fees for TVET programmes to attract a higher number of enrolments has also affected the quality of education at TVET institutes (Rong, 2012; Shenmiao, 2011).Therefore, the issue of dropping out from TVET programmes in developing countries has become more critical as compared to the issue of dropping out from mainstream education. However, as the present study has shown, vocational schools can improve its operational and learning environments by being able to motivate students to stay and finish their diplomas. Teacher and administration autonomy support is one effective way for students to have positive experiences about their course as the support would encourage them to learn, value learning, and also feel competent about themselves and thus, finish the course. However, the study was not without its limitations. For example, it solely relied on 
self-reported measures and did not include other methods of data collection which made it difficult to accurately estimate the effect of any latent variables. For future studies, researchers may want to apply a longitudinal design and collect more extensive dropout and school performance data.

\section{REFERENCES}

Alivernini, F. L. (2011). Relationship between socioeconomic status, self-efficacy, motivation, academic achievement and intention to drop out of high school: A longitudinal study. The Journal of Educational Research, 104, 241-252.

Asian Development Bank. (2008). Education and skills: Strategies for accelerated development in Asia and the Pacific. Technical Report (pp. 42-61). Manila: Phillipines.

Battin-Pearson, S., Newcomb, M. D., Abbott, R. D., Hill, K. G., Catalano, R. F., \& Hawkins, D. J. (2000). Predictors of early high school dropout: A test of five theories. Journal of Educational Psychology, 92, 568-582.

Báo cáo dạy nghề Việt Nam (2012). Tổng cục dạy nghề, Viện nghiên cúm khoa học dạy nghề, Nhà xuất bản lao động Hà Nội. TVET report Viet Nam 2012, General Department of Vocational Training, National Institute for Vocational Training. Hanoi: Labour Publishing House.

Chin, W. (1988). The partial least squares approach for structural equation modeling. In G.A. Marcoulides (Ed.) Modern Methods for Business Research (pp. 295-336). Mahwah, NJ: Lawrence Erlbaum Associates.

Deci, E. L., \& Ryan, R. M. (1985). Intrinsic motivation and selfdetermination in human behavior. New York: Plenum.

Deci, E. L., \& Ryan, R. M. (1991). A motivational approach to self: Integration in personality. In

R. Deinstbier (Ed.), Nebraska symposium on motivation: Perspectives on motivation (Vol. 38, pp. 237- 288). Lincoln, NE: University of Nebraska Press.

Deci, E.L., \& Ryan, R.M. (2000). The 'what' and 'why' of goal pursuits: human needs and the self-determination of behavior. Psychological Inquiry, 11, 227-268. 
Deci, E. L., \& Vansteenkiste, M. (2004). Self-determination theory and basic need satisfaction: Understanding human development in positive psychology. Recherché di Psichologia, 27, 17-34.

DHET (2014).Statistics on Post-School Education and Training in South Africa: 2012. Republic of South Africa: Department of Higher Education and Training.

Fornell, C., \& Larcker, D. F. (1981). Evaluating structural equation models with unobservable variables and measurement error. Journal of Marketing Research, 18 (1), 39-50.

Fowler, W. J., Jr., \& Walberg, H. J. (1991). School size, characteristics, and outcomes. Educational Evaluation and Policy Analysis, 13, 189- 202.

Haller, E. J., \& Virkler, S. J. (1993). Another look at rural-nonrural differences in students' educational aspirations. Journal of Research in Rural Education, 9, 170-178.

Hằng,B., Kaur, A., \& Patil, A. (2015). Impacts of school administration autonomy support on students` learning motivation and intentions to drop out of vocational school. International Journal of Quality Assurance in Engineering and Technology Education, 4(2), 1-12.

Hardre, P. L., \& Reeve, J. (2003). A motivational model of rural students' intentions to persist

versus drop out of high school. Journal of Educational Psychology, 95, 347-356.

Janjua, Y. \& Irfan, M. (2008). Situation analysis to support the programme design process for National Skills Strategy of the Islamic Republic of Pakistan. Islamabad: SEBCON (Pvt) Limited Socio-economic and Business Consultants.

Jeradechakul,W. (2013, October). TVET in the Context of Southeast Asia's Regional Integration. SEAMEO's Response Keynote Speech at Regional Conference on Vocational Teacher Education. Tongil University, Siping Campus, Shanghai, China.

Jordan, W. J., Lara, J., \& McPartland, J. M. (1996). Exploring the causes of early dropout among race-ethnic and gender groups. Youth \& Society, 28, 62-94.

Kaur, A, Awang-Hashim, R., \& Noman, M, (2015).Teacher autonomy support intervention as a classroom practice in a Thai school. Journal for Multicultural Education, 9 (1), 10 - 27. 
Kaur, A., Awang- Hashim, R., \& Noman, M. (2014). Teacher autonomy support: Does it hinder motivation among Thai Students? Malaysian Journal of Learning and Instruction, 11, 171-189.

Reeve, J. (2006). Teachers as facilitators: What autonomy-supportive teachers do and why their students benefit. Elementary School Journal, 106, 225-236.

Reeve, J., \& Jang, H. (2006). What teachers say and do to support students' autonomy during a learning activity. Journal of Educational Psychology, 98, 209-218.

Ringle, C. M., Wende, S., \& Becker, J. M. (2015). SmartPLS 3. Boenningstedt: SmartPLS GmbH.

Rong, W. (2012). To phase in free vocational secondary education for all: Not so fast.

Education \& Economy, 2, 1-6.

Rosenberg, J. (2011, October 25). Drop-out rate high in vocational training. The Sidney Morning Herald. Retrieved from http:// www.smh.com.au/national/education/dropout-rate-high-invocational-training-20111024-1mgeh.html

Ryan, R. M., \& Deci, E. L. (2000). Intrinsic and extrinsic motivations: classic definitions and new directions. Contemporary Educational Psychology, 25(1), 54-67.

Ryan, R., \& Grolnick, W. S. (1986). Origins and pawns in the classroom: Self-report and projective assessments of individual differences in children's perceptions. Journal of Personality and Social Psychology, 50, 550-558.

Sénécal C., Vallerand R. J., \& Pelletier L. G. (1992). Type de programme universitaire et sexe de l'étudiant : effet sur la perception du climat et sur la motivation. Revue des sciences de l'éducation, 18(3), 375-388.

Shenmiao, G. ( 2011). Causes and solutions for secondary vocational school dropout. Vocational Education Research, 11, 54-56.

UNESCO. (2012). Transforming Technical and Vocational Education and Training: Building skills for work and life. In Third International Congress on Technical and Vocational Education and Training Shanghai (pp. 1-14). Shanghai: People's Republic of China.

Vallerand, R. J. (1997). Toward a hierarchical model of intrinsic and extrinsic motivation. In M. Zanna (Ed.), Advances in experimental social psychology (pp. 271-360). New York: Academic Press. 
Vallerand, R. J., Blais, M. R., Briere, N. M., \& Pelletier, L. G. (1989). Construction et validation

de l'\&helle de Motivation en fklucation [Construction and validation of the Academic Motivation Scale]. Revue Canadienne des Sciences du Comportement, 21, 323-349.

Vallerand, R. J., Fortier, M. S., \& Guay, F. (1997). Self-determination and persistence in a real-life setting: Toward a motivational model of high school dropout. Journal of Personality and Social Psychology, 72, 1161- 1176.

Vansteenkiste, M., Zhou, M., Lens, W., \& Soenens, B. (2005). Experiences of autonomy and control among Chinese learners: Vitalizing or immobilizing? Journal of Educational Psychology, 96, 755-764.

Vallerand, R. J., \& Thill, E. E. (1993). Introduction au concept de motivation. In R. J. Vallerand \& E. E. Thill (Eds.), Introduction $a^{`}$ la psychologie de la motivation (pp. 3-40). Laval, QC: E' tudes Vivantes.

Williams, G. C., \& Deci, E. L. (1996). Internalization of biopsychological values by medical students: A test of selfdetermination theory. Journal of Personality and Social Psychology, 70, 767-779.

Yao, J., Yi, H., Zahang, L., Wang, H., Yang, C., Shi, Y., Chu,J., Loyalka, P., \& Rozelle, S. (2013). Exploring the dropout rates in China and causes of dropout in ppper secondary vocational schools in China. Working paper 261. Retrieved from https:// reap.fsi.stanford.edu/sites/default/files/Exploring_Dropout_ Rates_and_Causes_of_Dropout_in___Upper-Secondary_ Vocational_Schools_in_China.pdf 